\title{
069 \\ An investigation of the effectiveness of locally available materials as oil spill sorbents for Sri Lanka
}

\author{
L A C S Piyadasa, D K Weerakoon and S W K Kotagama \\ Department of Zoology, University of Colombo, Sri Lanka
}

The effectiveness of seven locally available natural organic materials as oil spill sorbents was tested The study specifically focused on determining, the behaviour of loose material on a layer of oil, oil sorption capacity of different types of materials and the viability of using them under actual field conditions. The seven natural organic materials were chosen based on their availability and cost. The amount of oil sorption by each was determined by the gravimetric method and the rate of sorption was determined. A commercially available synthetic oil sorbent, polyurethane, was used as the positive control. Out of the seven natural organic materials tested, human hair was found to be the most effective sorbent. Compared to the positive control, Polyurethane, there was no significant difference with respect to the oil sorption capacity of human hair. Therefore, all the subsequent experiments were carried out using human hair only. As hair has a tendency to sink in sea water after oil sorption, hair was compacted in to pillows to facilitate the recovery after sorption. First, the affect of the pillow thickness on the oil sorption capacity was tested. Oil sorption capacity increased significantly as the thickness of the pillow increased and a th ickness of $1 \mathrm{~cm}$ was found to yield the most efficient sorption. Then sorption capacity of oil by pillows was compared on a sea water oil interphase. only on oil and oil on sand. No significant difference was detected in the oil sorption capacity of hair filled pillows under these three conditions. Finally, a field trial was conducted where pillows were developed up to the size of commercially available synthetic pillows and placed on an artificially created oil spill and tested the oil sorption capacity under actual field conditions. A total of four pillows were used for the field trial and the pillows were removed at different time intervals after placing it on the artificial oil slick. The results of this experiment were not conclusive as amount of oil absorbed by all four pillows did not reach the expected value calculated based on results obtained during laboratory experiments, due to several shortcomings in the experimental design. The results of this study clearly demonstrate that human hair can be used as an effective oil sorption material. As waste human hair is cheap and readily available, it is a much more viable alternative to expensive synthetic organic material available in the market.

\section{$\underline{070}$ \\ Studies on utilization of sewage waste water for greening wastelands through afforestation}

\author{
M P Divya, K Srinivasan and M G Rao \\ Forest College and Research Institute, Tamil Nadu Agricultural University, India
}

One of the major burning problems in urban areas is the disposal of sewage water, which degrades the environment, and as well as creates health hazards to human beings. One opening to this bottleneck is that this sewage water could be diverted for irrigation purpose especially for afforestation purpose. Sewage water provides nutrients and using it for irrigation has been found to enrich soil, improve uptake of plants and ameliorate degraded soils. It was found that sewage water irrigated tree species recorded maximum height and basal diameter when compared to bore well water irrigation. It showed that it boosted the growth of tree species. Hence the utilization of sewage water as irrigation water for tree crops is the one of best option for increasing biomass and protecting environment deterioration from deforestation of land and water by sewage water.

In this context, a field experiment was conducted at sewage farm and the following tree species viz., Eucalyptus tereticornis, Tectona grandis, Casuarina equisetifolia, Azadirachta indica and Acacia nilotica were planted and irrigated with sewage water at 2 weeks interval. The same 5 species were also planted near the sewage farm and irrigated with bore well water. The growth parameters viz., height and basal diameter were recorded at periodical interval. The results revealed that the height and basal diameter of all the five selected tree species were higher under sewage water irrigation when compared to bore well water irrigation. The results inferred that at $3 \mathrm{MAP}$, the percent increase in height and basal diameter respectively was $15 \%$ and $18 \%$ for Casuarina equisetifolia, $39 \%$ and

Proceedings of the International Forestry and Environment Simposium 2006 of the

Depariment of Forestry and Environmental Science. University of Sri Jayewardenepura. Sri Lanka 